\title{
Designing for Failure in the Design/Build Studio
}

\author{
CHAD KRAUS \\ University of Kansas
}

The designbuild studio, as a form of academic live project, straddles academia and practice. The intersection of experiential learning with real world contexts raises a potentially complicated ethical dilemma: In striving to maximize student learning for each student, while simultaneously striving to deliver the best possible work of architecture, what happens when these two goals find themselves at odds? This paper explores salutary failure - of architectural product and, occasionally, of architectural pedagogy - in the designbuild studio through the lens of a series of designbuild projects. These explorations include strategies for anticipating and guiding potential failures and developing the generosity to embrace failure.

\section{MOTIVATIONS FOR DESIGNING FOR FAILURE}

The designbuild studio, as a form of academic live project, engages in a level of uncertainty uncharacteristic of most educational models. From collaborating with non-academic entities to embracing real circumstances, these endeavors straddle the conventionally distinct realms of academia and practice. What follows are a few remarks concerning the design and construction of permanent public projects and the role of failure as a pedagogical framework. Designing for failure in the designbuild studio, as opposed to designing to prevent failure, is both ideologically and pragmatically motivated - ideological in that much research has demonstrated the significant benefits of failure, and pragmatic in that failure is, to a large extent, unavoidable. As Elon Musk has said, "Failure is an option here. If things are not failing, you are not innovating enough." ${ }^{1}$

Successes have been shown to increase the body's production of testosterone and dopamine, altering brain functioning and resulting in increased focus on goals and on achieving awards. ${ }^{2}$ However, Individuals who succeed early and often avoid being tested by failure, and this can lead to a more rigid, close-minded, and less creative disposition. Complacency and risk-aversion are potential liabilities of success. ${ }^{3}$ Patterns of small successes can be crippling to personal growth and lead to larger systematic failures. "It is paradoxical but true to say that 'Failure was born of success'". ${ }^{4}$ Not coincidentally, young Americans - coddled as children, grade-inflated, and awarded for participation - have been repeatedly characterized as risk-averse and complacent. ${ }^{5}$

Conversely, patterns of small failures can lead to heightened achievement. Success following multiple failures can often result in developing grit. Psychologist Angela Duckworth argues that grit is perhaps the single most important trait for long-term success. ${ }^{6}$ Well-intentioned failures lead to adaptive behaviors and the cultivation of emotional intelligence. From a pedagogical perspective, intentional, strategic failure could not only foster durable lessons, if properly structured, could build confidence without arrogance.

\section{ARCHITECTURAL PROJECT OR ARCHITECTURAL PEDAGOGY}

I teach the Dirt Works Studio, a required, third-year, designbuild studio embedded into the core curriculum of the five-year professional program at the University of Kansas. Each semester, the studio is comprised of fifteen to twenty students and one instructor. Over the past seven years, we have developed a pattern of working with a client or community partner and a defined set of stakeholders to deliver permanent public projects.

The scale of the projects is modest enough to enable design and construction to occur within a fifteen-week timeframe by a single cohort of students; however, to do this requires a lot of collaboration and some careful division of labor. The pedagogical aims of the studio are that each student receives a whole designbuild education, not a myopic focus on one part. It may be tempting to divide the studio and have each student focus on only one type of task at the expense of a holistic education. The extreme alternative would be to have each student design and build her/his own project, but this would come at the expense of project complexity and impact. It is essential, then, that the studio balance pedagogical and professional obligations.

As stakeholders in the live architectural project, clients, community partners, and external collaborators frequently contribute an additional set of performance criteria to the already defined pedagogical intent of the studio. In addition to a myriad of educational goals, the studio may enter into a quasi-professional context in which real resources - time, money, land, and/or materials - are dedicated to the project, and real outcomes - functional, durable, cost-effective, and aesthetically-pleasing structures/spaces - are expected. The intersection of experiential learning with real world contexts raises a potentially complicated ethical dilemma: In striving to maximize student learning for each student, while simultaneously striving to deliver the best possible work of architecture, what happens when these two goals find themselves at odds? 


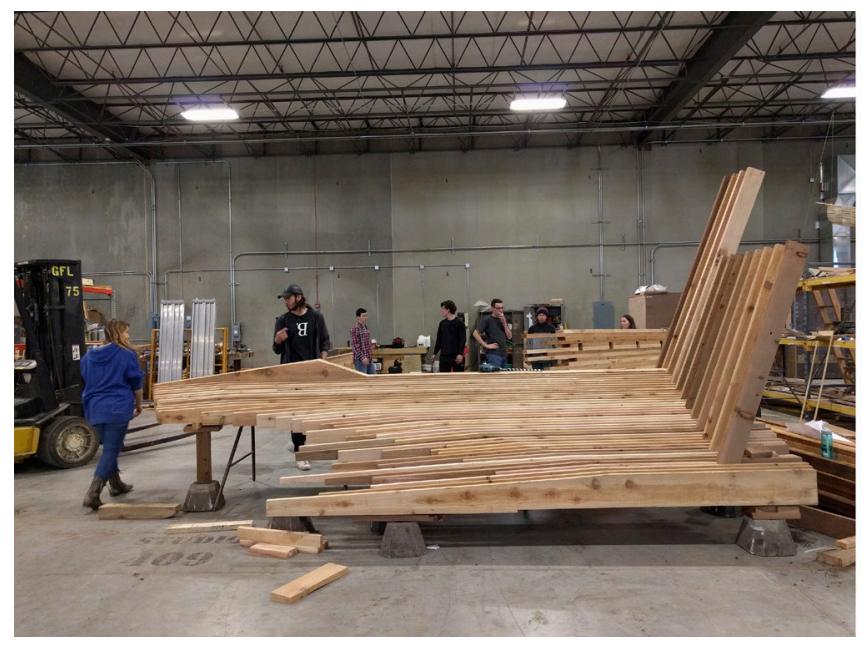

Figure 1: Pre-bulding the mass timber canopy of the Sensory Pavilion (left) and the finished outcome (right), 2016. Photography by Chad Kraus.

In a conversation with designbuild pioneer Dan Rockhill, I asked him some questions on this particular subject:

CK: Unlike most design studios - which are largely hypothetical - designbuild studios such as Studio 804 serve not only internal pedagogical obligations but also external obligations. These buildings have to perform. How do you balance these obligations? For example, a student is struggling to understand a particular problem. Do you take the time to ensure that the student learns what you have set out to teach them, even if this negatively impacts the schedule of the project, or, given the pressures of completing the project on time and on budget, do you push it forward even if you risk missing a teaching opportunity?

$D R$ : I tend to privilege student learning, if nothing else for the sake of quality. I do it by intimidation. There is a lot of work that gets torn out and redone. Fortunately, I have had the experience to know what to look for. I know where the quicksand is. I try to catch them before it becomes a nightmare. We do not do bad work. I am very insistent on that. The work should be done with pride; an element of craft has to be evident. This is one of the more difficult aspects to teach. They need to understand this first hand, and once they do, they can almost always predict what I will say when they show me what they have done. I am insistent that we conduct ourselves as professionals, both through design and construction documentation but also in the actual built work. It takes a while for them to come to terms with that.

CK: In the design studio, failure can be a viable outcome; some of the best lessons arise when students try something very risky and ultimately "fail" to bring the idea to fruition. There can be a lot to take away from these types of experiences, sort of "failing up", as it were. In the past you have criticized architects for wanting to solve everything on paper and have praised the ability to be agile in the face of inevitable

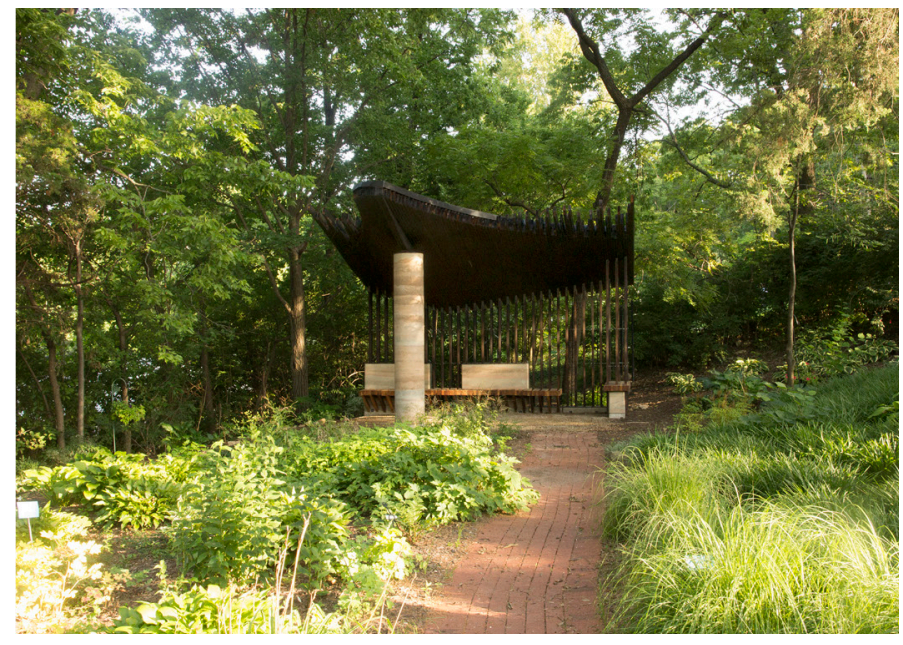

uncertainty during the construction process. In designbuild studios such as Studio 804, is there any opportunity for productive failure?

DR: Part of the enjoyment of designbuild is that we are afforded the luxury of building at full scale. We can examine multiple ideas through mockups and then stand back and observe it in its final context and test the ideas. I will usually put a time cap on it - "let's give this our best half day." We have a building to build, so we just keep pushing. In the case of the East Lawrence House, we built some pretty awful iterations in the process, but we saw the potential and drove the mockups until we were satisfied. Some days I just have to say no and pull the plug on the idea. I am fairly dictatorial. In their professional careers it will not always be their favorite lesson, but it is an important one nonetheless. ${ }^{7}$

Professor Rockhill's responses to my questions suggest a confident and experienced designbuild educator, but they also reveal the struggle that we all face when it comes to balancing what is best for our students' education versus what is best for our small contribution to the built environment. He states that he "privilege(s) student learning" while recognizing that "we have a building to build", and that one must occasionally "pull the plug" and take on a more "dictatorial" approach, which may ultimately come at the expense of student learning.

In addition to managing risks, the designbuild educator must establish a clear understanding between the studio and the community partner. This understanding can take the form of a memorandum of understanding or similar written contractual or verbal arrangement. Yet, even with carefully managed risks and expectations, the possibility remains that our best intentions can go awry. In my experience it is not a question of whether this will happen but rather, when it does happen, how will the designbuild educator react?

\section{ANTICIPATING AND GUIDING POTENTIAL FAILURE}

In construction it is possible to predict which trades or materials require a greater level of tolerance than others. One often 


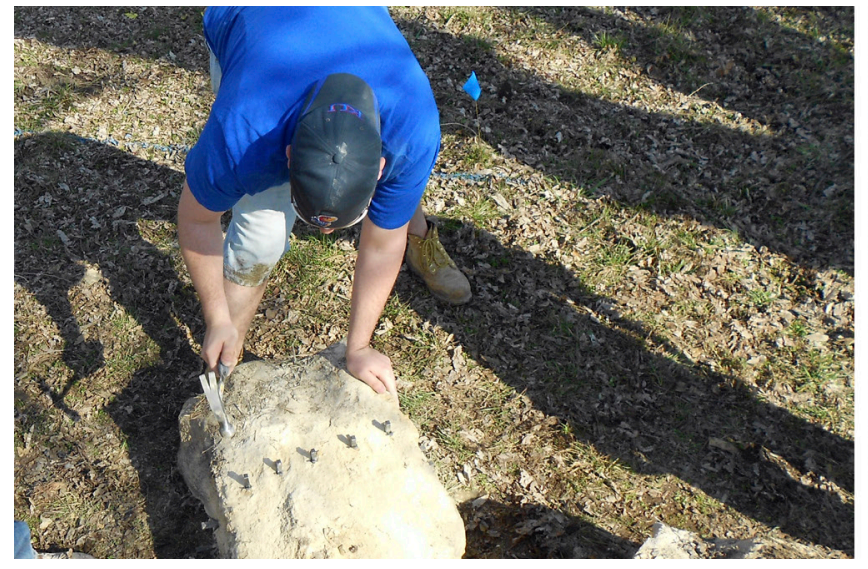

Figure 2: Shifting course in the building of the Field Station Gateway, 2013. Photography by Chad Kraus and Matt Benfer.

adopts a strategy for absorbing error, such as a reveal at a joint between two dissimilar materials, or a scribe detail mitigating differences between high-precision prefabricated elements and less precise site-built ones. In such instances, we anticipate and design for potential errors before they arise. Similarly, if we know from past experience and/or empirical data that a material like concrete is prone to cracking, we attempt to control cracks in pre-defined locations, i.e. control joints. We accept and invite small errors to prevent larger ones. In this instance, the failure is all but inevitable, the only question being where we will allow the material to fail.

In the designbuild studio, analogous strategies can be useful in anticipating and guiding failures, but these must be designed into the structure of the studio prior to the error arising in the project. A framework I have used to harness failure starts with:

1) Sharing knowledge and principles, modeling creative and critical thinking, and guiding students through the process, so they are well equipped to make intelligent decisions.

2) Empowering students with the responsibility to execute on what they have learned, with a firm but invisible hand. It is important to minimize the temptation to prevent all failures, but build in sufficient time and resources for recovery.

3) Harnessing the opportunity of failures by encouraging students to own them and learn from them. It is important to avoid shielding students from the consequences of their mistakes, but also to provide a tolerant atmosphere so they can cultivate their passion and perseverance.

4) Reflecting on failure and modeling mature decision making to support students as they overcome failure. It is critical that an educator defines what success and failure look like, and that all students and stakeholders share a similar understanding.

Especially when taking on permanent projects, designbuild educators must clearly delineate and manage the scope of the

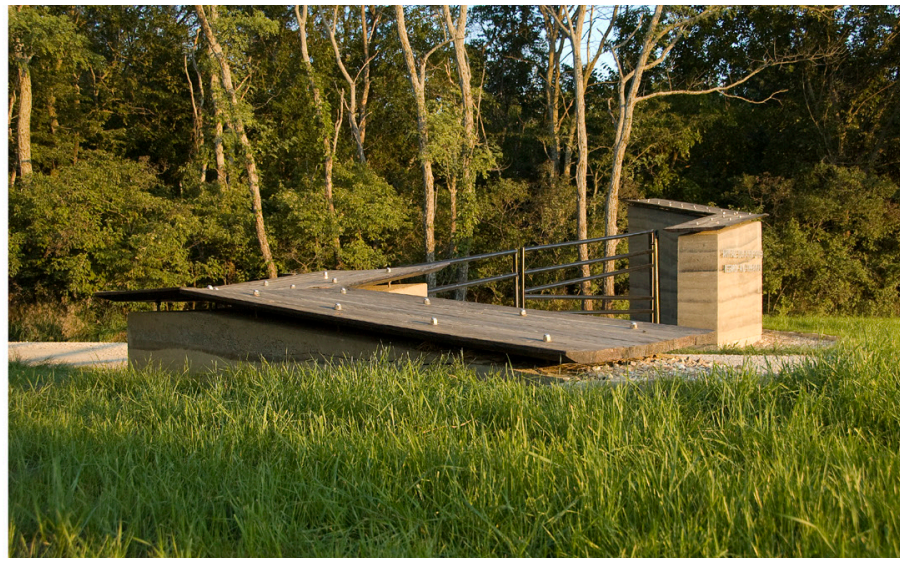

project; preemptively test its most challenging aspects; build in adequate time and resources to recover from isolated failures; be willing to remake portions of the project as necessary to maintain quality; and limit the number of high risk variables.

During construction of the Sensory Pavilion, the Dirt Works Studio built multiple mockups of a screw-laminated mass timber roof before finalizing the design. Even then, the studio opted to prebuild the entire roof at full-scale in our workshop before building it again on site. The prebuild allowed us to prepare the more than 160 unique pieces of lumber and to test and make adjustments in a controlled setting. It also allowed us to work through the means and methods of construction prior to being on site, where additional challenges complicate every step. As a result of the prebuild, the studio made critical modifications to the design and sequencing of the roof construction.

\section{DELIGHTING IN THE WORKMANSHIP OF RISK}

Every act of making falls somewhere along a continuum between certainty and uncertainty. Celebrated furniture maker and educator David Pye described these poles as the workmanship of certainty and the workmanship of risk. ${ }^{8}$ The workmanship of certainty commonly describes craftwork done by a machine or through a process in which the outcome is highly predictable and replicable. The workmanship of risk describes craftwork done in a manner in which the outcome is never assured and at any given moment the work could fail. It is important to know where along the continuum a particular part of the project ought to fall, and to plan accordingly.

The Dirt Works Studio often employs design strategies that benefit from expressing traces of the thing having been made. We are drawn - both by temperament and by intent - to materials or approaches that are all the more beautiful or compelling when they are not perfectly executed - the rawness of rammed earth, the generosity of board formed concrete, the variation of charred timber. Yet there are instances when the appropriate material for a given situation calls for a high level of precision. In these cases, we look for opportunities to take up potential errors elsewhere, such as with slotted connections or isolated systems. 


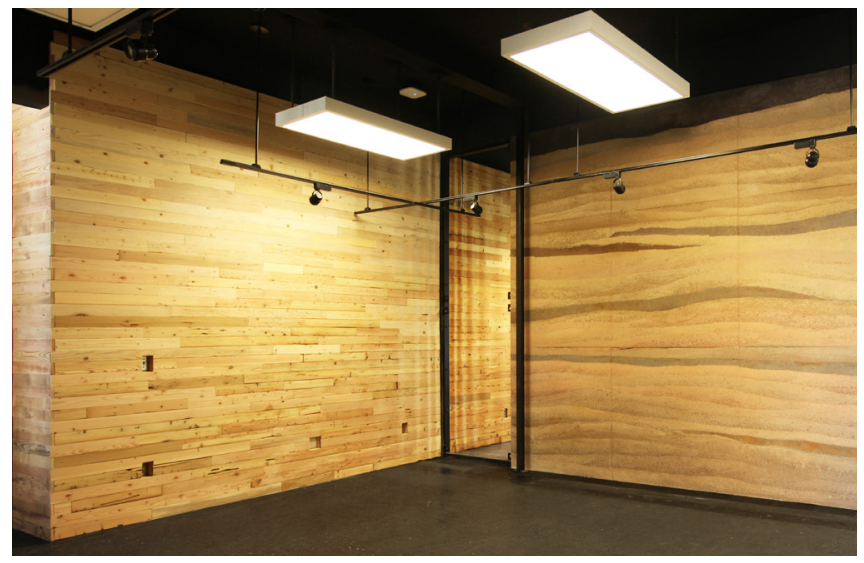

Figure 3: Nearing completion on the Mud Hut Rebirth, moments before the fire marshal debacle, 2015. Photography by Chad Kraus.

Identifying probable failure faults may require that an educator develop sufficient experience to recognize the strengths and limitations of her/his students. It may also mean maintaining multiple scenarios at any given point in the project and being able to adapt in situ. Agility in the face of the unknown is, after all, one of the unique provinces of designbuild initiatives - to be able to respond and adapt to conditions as they unfold without losing sight of the essential design principles.

During the Field Station Gateway project - a rammed earth and steel gateway marking the entrance into a research and nature reserve -the studio had planned to dredge limestone boulders from a nearby pond, and to divide them into rough ashlar blocks using a plug and feather technique. We were drawn to this idea for its cost effectiveness, its relationship to the place, and the mission of our client. We anticipated the risks involved in a technique that we had never attempted, on a stone we knew little about. We made sure to have a plan B.

As we began to shape the stone it became increasingly evident that the existing veins in the stone were more likely to guide the breaks than our intended locations. The stone was very hard and permitted seams to open up wherever it had already decided. We began to revisit alternative strategies born out of our earlier discussions of the place and its history. A clear theoretical position allowed us to consider multiple satisfying solutions to the problem at hand.

Shifting from stone to a charred timber plane protecting the rammed earth mass was at once a failure and an opportunity to revisit earlier notions of prairie fire in the central plains. The decision to abandon the stonework was made after the rammed earth mass had been completed, giving us a new perspective from which to judge our solution. The disruption in the work provided a pause to evaluate alternative solutions. A timber plane appearing to hover above the earthen mass, though not our original intention, was closer to our initial concepts for the project.

\section{LEARNING FROM DETRIMENTAL FAILURE}

Despite every precaution, the live project offers no guarantees against detrimental failure. In the fourth year of the Dirt Works Studio, we were tasked with a modest renovation of an existing, seemingly unremarkable, campus building that had over the decades experienced a multitude of haphazard modifications. During its tumultuous $70+$ years, the building was used for everything from a radio station to textile studios, its roof was blown up twice during its years as a cryogenics laboratory, and its maintenance was generally neglected.

Yet, the building had a remarkable origin - it was an early and regionally unique example of a rammed earth block building. By the time the Dirt Works Studio was asked to breath new life into it, the interior was a mess of dim and tangled corridors connecting a series of unremarkable rooms. The architecture school had recently converted half of the building into a digital fabrication and robotics lab.

To honor and make more explicit the story of the building as an earthen structure, the studio decided to replace a non-descript load-bearing wall in the center of the building opposite the main entry with a new, exposed, rammed earth wall. To celebrate the new digital fabrication functions, the studio decided to wrap the corridor walls of that portion of the building with a subtly undulating, digitally fabricated, reclaimed timber wall.

A key miscommunication occurred early in the project regarding the fire rating of the corridors and was not caught until the project was nearing completion. After a heroic effort to complete the project in less than eight weeks, the studio learned from the university fire marshal that all of the newly fabricated and installed timber cladding in the corridors must be torn out and the glazed doors separating the new studio space from the corridor would have to be fire-rated.

While this setback was unfortunate, an opportunity arose for a unique teaching moment regarding Authorities Having Jurisdiction, fire-code, flame-spread classifications, etc. In the end, the studio was able to adapt to the situation and complete the project on time and under budget, albeit not according to the original design.

Interestingly, in this particular case, the pedagogical mission was enhanced. The students had learned all that they were going to learn from the original design and construction. However, a most difficult but equally unforgettable lesson was learned. Like any good come-from-behind story, overcoming setbacks and seeing the project through builds character, grit, and confidence. The students learned that failure was something they could live through; that, although painful, it did not have to be paralyzing. 


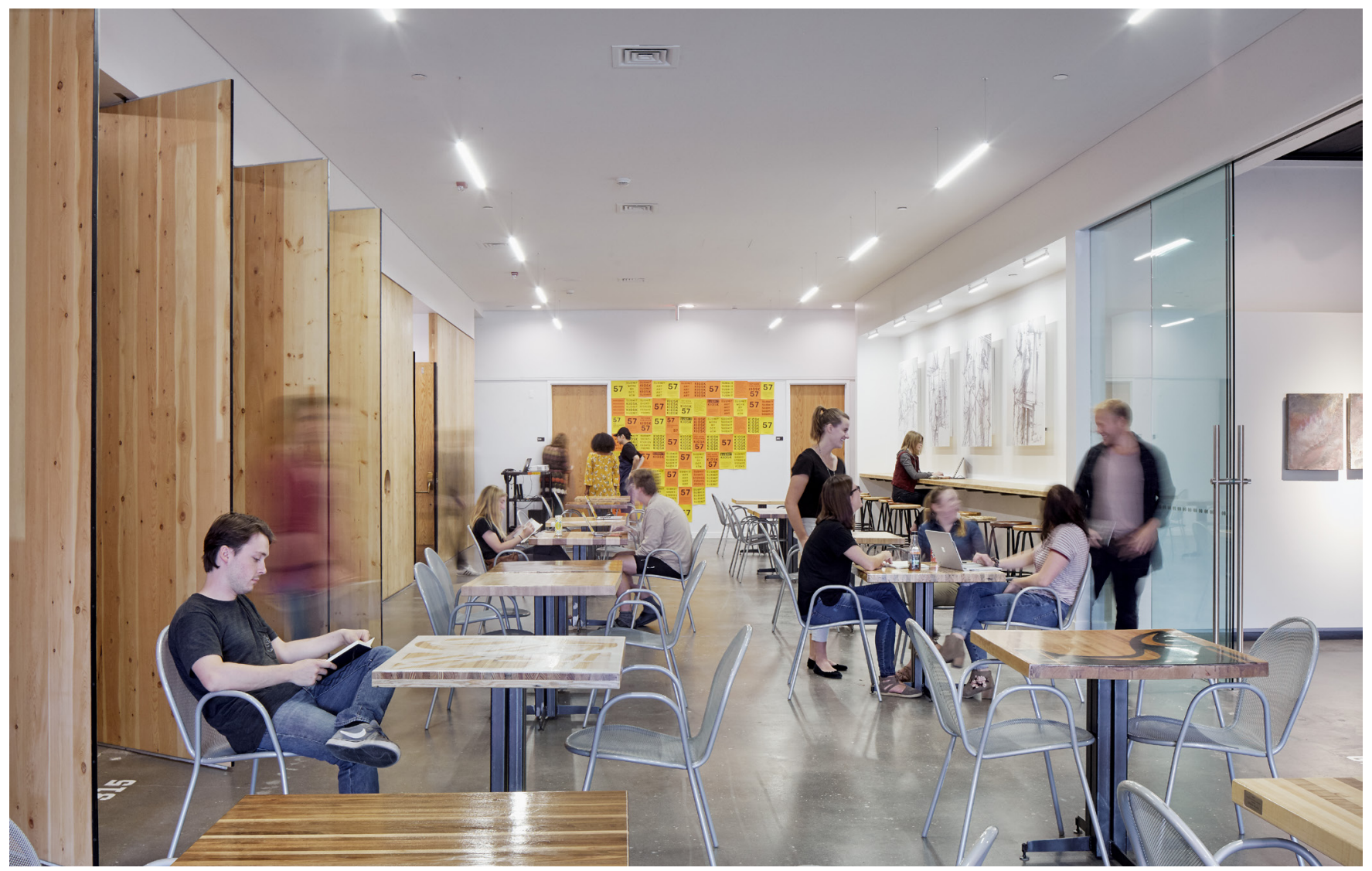

Figure 4: Chalmers Hall Renovation, 2017. Photography by Mike Sinclair.

\section{SALUTARY OR PRODUCTIVE FAILURE}

Despite careful planning and measured expectations and despite anticipating and preemptively guiding potential failure points, error creeps in. In his seminal work, The Craftsman, sociologist Richard Sennett describes a kind of productive or salutary failure when reflecting on John Ruskin's pursuit of craft, stating, "Ruskin sought to instill in craftsmen of all sorts the desire, indeed the demand, for a lost space of freedom; it would be a free space in which people can experiment, a supportive space in which they could at least temporarily lose control. This is a condition for which people will have to fight in modern society. Ruskin believed that the rigors of the industrial age work against experiences of free experiment and salutary failure...the craftsman serves as an emblem for all people in the very need of the opportunity for "hesitation...mistakes". ${ }^{9}$

In the renovation of Chalmers Hall, the Dirt Works Studio was drawn to cross laminated timber (CLT) for major new elements of the project-a sixty-foot-long wall of partially operable solid wood panels on one side and a 30-foot-long bar counter on the other, reinforcing the central spine that connects the two halves of the original building. After receiving the shipment of raw CLT panels, the studio mortised hinges, sweeps, and locking bolts; eased corners; cut half-lap joints; and applied finishes.
The CLT bar counter was comprised of three panels, each with straight or half-lapped edges. The panels needed to be trimmed to fit precisely in the already framed and finished niche. Due to the cost of the panels and their long lead-time, we knew that we had to be careful not to mar the surfaces or to err in trimming or finishing the edges. I emphatically stressed the need to measure twice and cut once, went over the process carefully, and even insisted on my students working in pairs to double check each other before committing to irreversible operations. What could go wrong?

The first panel was duly worked and installed properly. Next, the second panel was worked and installed as well. Finally, the third panel was trimmed to fit the remaining opening. How the error occurred became obvious shortly after the deed was done. In any case, the final panel was cut exactly one half-lap too short. The cut was made precisely; however, the thinking was imprecise. The responsible students were horrified, and consequently approached me with trepidation to explain the mishap. With a looming deadline and a limited budget, what were we to do? The studio regrouped to discuss our options. We could fur out the side of the niche, but that could get messy, and would require that we uninstall and redo a lot of work. "Damn, too bad there is no 'stretch' command in real life" one of my students could be heard muttering. "Well, we could carefully glue the trimmed piece back on and re-trim to the correct size", another offered. No, that would be unacceptable, a chorus of voices returned. 


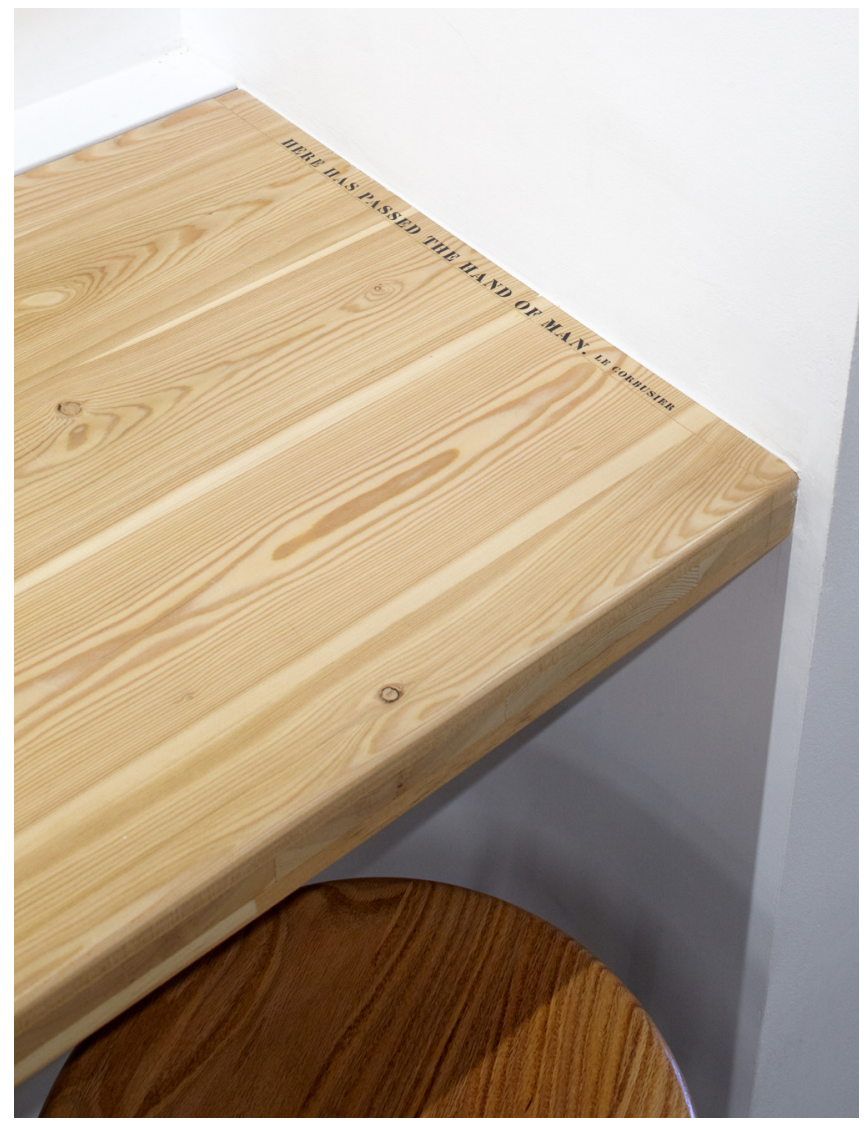

Figure 5: "Here has passed the hand of man." inscribed on the CLT bar in Chalmers Hall, 2017. Photography by Mike Sinclair.

The Dirt Works Studio decided we would not try to fix and conceal our mistake in shame; instead, we would acknowledge our fallibility and play up the error as evidence of handcraft. The over-trimmed piece of CLT was, in fact, carefully glued back on and re-trimmed to the correct length. Then, along the error seam, we inscribed the words, "Here has passed the hand of man", a quotation attributed to Le Corbusier, in response to an error during the construction of the Convent Sainte-Marie de la Tourette. ${ }^{10}$ The quotation was inked by hand directly onto the CLT using Le Corbusier's stencils. This little architectural Easter egg quickly became a favorite moment in the project, and has come to be appreciated by many users of the space.

\section{ARCHITECTURAL PROJECT AND ARCHITECTURAL PEDAGOGY}

While bumbling the CLT bar could have negatively impacted the project as a whole, that error was never going to be catastrophic. There are, however, some failures that are far too consequential to be allowed to happen. While some designbuild educators are loath to admit it, there are instances when the circumstances of the project requires that potential lessons are interrupted or circumvented in order to ensure that the quality of the eventual project is not compromised, or that safety is not jeopardized. In these situations, all is not lost, pedagogically speaking. The designbuild studio promotes embodied learning even when lessons cannot be imparted directly. During the Chalmers Hall renovation, my students did not perform, on their own, the electrical, plumbing, or fire safety work. Instead, they worked alongside tradespeople, and in some cases, shadowed their work and provided assistance. Despite not performing the work themselves, they gained an understanding of these trades that is difficult to acquire in conventional coursework.

As the director of the Dirt Works Studio, I have endeavored to teach my students to take calculated risks, to accept and learn from mistakes, to persevere through difficulty, and to cultivate their passions. In each instance of failure, I have delighted to witness their strength of character and willingness to overcome adversity. However, during critical junctures in the design and/ or construction of the Studio's projects, I frequently intercede to keep the ship pointing in the right direction. It may be true that I preempt some potentially useful experiential lessons. Yet, modeling the behavior of a professional architect is, in and of itself, a teaching opportunity. Students learn by observing their instructor engage with code officials, weld sensitive structural components, or problem-solve alongside them. Even if this were not the case, pragmatically, the greater good is achieved by maintaining the quality of the studio so that it may survive to offer future cohorts of students a designbuild experience.

When attempting to strike a balance between maintaining the craft of pedagogy with the craft of practice, it is useful to consider that designing for failure in the designbuild studio can not only offer deep lessons, it can have salutary effects on the work itself.

\section{ENDNOTES}

1 Jennifer Reingold, "Hondas in Space," Fast Company, February 1, 2005, https:// www.fastcompany.com/52065/hondas-space.

2 Ian H. Robertson, The Winner Effect: the Neuroscience of Success and Failure (New York: Thomas Dunne Books, 2012).

3 Sim B. Sitkin, "Learning Through Failure: The Strategy of Small Losses," Research in Organizational Behavior, vol. 14 (March 1992): 234.

4 Sitkin, "Learning," 234, quoting Ikujiro Nonaka.

5 Tyler Cowen, Complacent Class: The Self-Defeating Quest for the American Dream (New York: St. Martin's Press, 2017). Dan Moskowitz, “Are Millennials Risk Averse or Risk Takers?," Investopedia, July8, 2015, https://www.investopedia. com/articles/investing/070815/are-millennials-risk-averse-or-risk-takers. asp. Don Lee, "Millennials Aren't Big Spenders or Risk-Takers, and That's Going to Reshape the Economy," LA Times, October 10, 2016, http://www.latimes. com/business/la-fi-the-millennial-factor-20161010-snap-story.html. Natalie Bacon, "Why Millennials Choose To Join Corporate America Over Becoming Entrepreneurs," Forbes, November 17, 2016, https://www.forbes.com/sites/ under30network/2016/11/17/why-millennials-choose-to-join-corporateamerica-over-becoming-entrepreneurs/\#78a53bc02d91.

6 Angela Duckworth, Grit: The Power of Passion and Perseverance (New York: Scribner, 2016).

7 Dan Rockhill and Chad Kraus, "Work Ethic, Ethical Work" in Designbuild Education, ed. Chad Kraus (New York: Routledge, 2017), 214-229.

8 David Pye, The Nature and Art of Workmanship (New York: Bloomsbury Academic, 2015).

9 Richard Sennett, The Craftsman (New Haven: Yale University Press, 2009).

10 Philippe Potié, Le Corbusier: Le Couvent Sainte Marie De La Tourette (Basel: Birkhäuser, 2001). 